\title{
Primary cardiac tumors: Rare but important
}

\author{
John S. Ikonomidis, MD, PhD
}

From the Division of Cardiothoracic Surgery, Medical University of South Carolina, Charleston, SC.

Disclosures: Author has nothing to disclose with regard to commercial support.

Received for publication June 30, 2015; accepted for publication June 30, 2015; available ahead of print July 28, 2015 .

Address for reprints: John S. Ikonomidis, MD, PhD, Division of Cardiothoracic Surgery, Suite BM 282, 114 Doughty St, Charleston, SC 29425 (E-mail: ikonomij@musc.edu).

J Thorac Cardiovasc Surg 2015;150:e54

$0022-5223 / \$ 36.00$

Copyright (c) 2015 by The American Association for Thoracic Surgery

http://dx.doi.org/10.1016/j.jtcvs.2015.06.085

In this month's issue of the Journal of Thoracic and Cardiovascular Surgery, Sánchez-Enrique and associates ${ }^{1}$ present a case of a large right atrial hemangioma that was found incidentally in a 74-year-old symptom-free man and successfully resected. Hemangiomas are uncommon cardiac tumors that are found in the right atrium in about $26 \%$ of cases. An independent predictor of hemangioma-related preoperative death is tumor location along the interatrial or interventricular septum. Although radiotherapy, corticosteroids, and $\beta$-receptorblocking agents have been successful in the conservative management of these patients, surgical resection is generally indicated because of the high incidence of severe complications, including embolism, cavitary obstruction, and coronary steal. ${ }^{2}$ It is remarkable that even though the tumor had occupied most of the right atrial cavity, there was no evidence of hemodynamic obstruction and the patient was symptom free. Clear intraoperative, echocardiographic, angiographic, and magnetic resonance images are provided to show the anatomy of the tumor, its blood supply originating from the right coronary artery, and the heterogeneous morphology of the tumor. Detailed gross and histologic images show that this particular tumor possessed qualities of all 3 classifications of hemangioma: cavernous, capillary, and arteriovenous.

Primary cardiac tumors are rare and often serendipitously discovered in the absence of symptoms. A careful evaluation

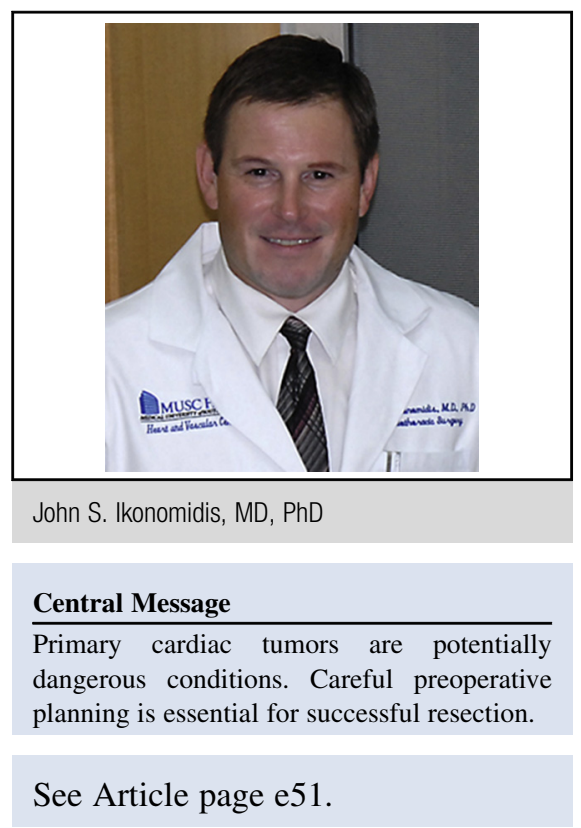

of the tumor must be undertaken for a full understanding of the anatomy and the feasibility of resection. In general, it is not possible to overstudy these patients, because any and all pieces of information could prove useful. Sánchez-Enrique and associates ${ }^{1}$ completed their preoperative work-up in comprehensive fashion, permitting surgical resection with a high probability of success.

\section{References}

1. Sánchez-Enrique C, Vivas D, Alcázar MC, Vilacosta I. Giant right atrial hemangioma: correlation between magnetic resonance imaging and histopathologic evaluation. J Thorac Cardiovasc Surg. 2015;150:e51-3.

2. Li W, Teng P, Xu H, Ma L, Ni Y. Cardiac hemangioma: a comprehensive analysis of 200 cases. Ann Thorac Surg. 2015;99:2246-52. 